\title{
Surgical septal myectomy: An enduring but evolving treatment for obstructive hypertrophic cardiomyopathy
}

\author{
Francis D. Pagani, MD, PhD
}

\author{
From the Department of Cardiac Surgery, University of Michigan, Ann Arbor, Mich. \\ Disclosures: Author has nothing to disclose with regard to commercial support. \\ Received for publication March 5, 2016; accepted for publication March 8, 2016; available ahead of print \\ April 13, 2016 \\ Address for reprints: Francis D. Pagani, MD, PhD, Department of Cardiac Surgery, University of Michigan, 5161 \\ Cardiovascular Center, 1500 East Medical Center Dr, Ann Arbor, MI 48109 (E-mail: fpagani@umich.edu). \\ J Thorac Cardiovasc Surg 2016;152:469-70 \\ 0022-5223/\$36.00 \\ Copyright (C) 2016 by The American Association for Thoracic Surgery \\ http://dx.doi.org/10.1016/j.jtcvs.2016.03.025
}

Hypertrophic cardiomyopathy (HCM) is the most common genetic cardiac disorder with a prevalence of $0.2 \%$ (1:500) in the adult general population, affecting approximately 600,000 people in the United States. ${ }^{1} \mathrm{HCM}$ is the result of genetic mutations in the beta-myosin heavy chain that manifest through an autosomal dominant pattern of inheritance. ${ }^{2} \mathrm{HCM}$ is identified clinically by the presence of myocardial hypertrophy in the absence of systemic diseases (eg, aortic stenosis and amyloidosis) that can elicit pathologic forms of cardiac hypertrophy. ${ }^{1,2}$ The majority of patients with HCM will have dynamic obstruction of the left ventricular outflow tract (LVOT) from septal hypertrophy, causing symptoms of exertional dyspnea, angina, and near syncope or syncope.

Septal myectomy was developed from early work at the National Institutes of Health. ${ }^{2}$ Transaortic septal myectomy currently is considered the gold standard of care for septal reduction therapies for patients with dynamic LVOT obstruction. ${ }^{3}$ Resection of the basal septal hypertrophy eliminates both LVOT obstruction and associated systolic anterior motion of the mitral valve (MV) and secondary MV regurgitation. An overwhelming majority of patients experience relief of symptoms and return to an excellent functional status. Of note, septal myectomy provides survival equivalent to that of the general population and reduces the risk of sudden death. ${ }^{4}$ Septal myectomy has contributed to the overall reduction in mortality associated with HCM over the past 10 years. ${ }^{2}$

Over the past 2 decades, septal myectomy has undergone significant evolution in surgical technique and approach. ${ }^{4}$ Mortality for septal myectomy is now substantially less than $1 \%$ at experienced centers with only rare occurrences of ventricular septal defect or aortic valve injury. ${ }^{1-4}$ The improved results of the procedure have resulted from modern myocardial preservation and improvements in postoperative management along with other advances in surgical techniques, such as extending the myectomy distally to the base of the papillary muscles (ie, extended septal myectomy) and recognition of numerous concomitant intraventricular abnormalities of the MV

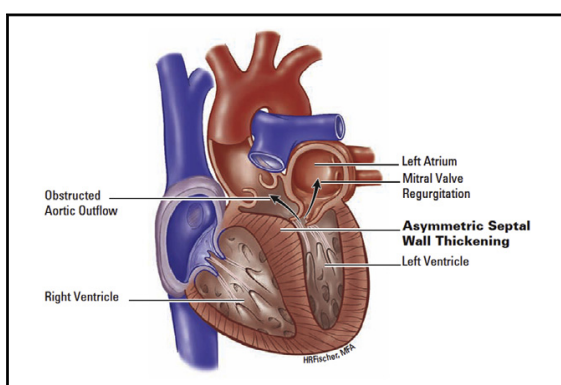

Extended surgical septal myectomy for obstructive HCM

\section{Central Message}

Myectomy for obstructive HCM has evolved with greater understanding of associated intraventricular anomalies.

See Article page 461 .

apparatus, including accessory papillary muscles, anomalous papillary muscle origins and insertions, fusion of the anterior papillary muscle with the septum or left ventricular (LV) free wall, and abnormal chordae tendineae (false cords) that attach to the ventricular septum or free wall. ${ }^{3,4}$ Severe hypertrophied papillary muscles or exaggerated anterior displacement of the anterolateral papillary muscle may lead to obstruction at both the level of the LVOT and the level of the midventricle. ${ }^{3,4}$ Elongated $\mathrm{MV}$ leaflets are an abnormal finding that contribute to dynamic LVOT obstruction. ${ }^{3,4}$ Excising accessory muscle bundles and dividing anomalous attachments between the subvalvular apparatus and septum or free wall and preserving attachments to the leading edge of the anterior leaflet are important additional surgical techniques to the extended septal myectomy. ${ }^{3,4}$ MV repair techniques, including chordal cutting, chordal extension or neochordal augmentation with posterior relocation, or plication of the leaflets to reduce length and mobilization of the papillary muscles, have contributed significantly to sustained reductions in LV gradients and have now avoided the need for MV replacement unless intrinsic unrepairable degenerative MV disease is present. $^{3,4}$ If these anomalies are not recognized and treated at the time of myectomy, incomplete relief of LVOT obstruction may occur.

In this issue of the Journal, Wang and colleagues ${ }^{5}$ have reported on the results of surgical septal myectomy in 277 


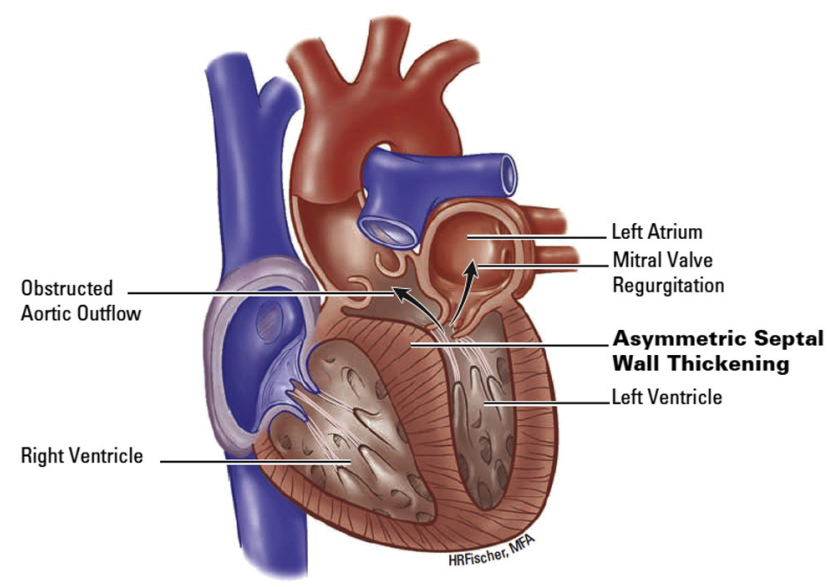

FIGURE 1. Extended surgical septal myectomy for obstructive hypertrophic cardiomyopathy.

consecutive patients with obstructive HCM (Figure 1). Operative mortality was $0.72 \%$, and LVOT gradient decreased from a median of $78 \mathrm{~mm} \mathrm{Hg}$ to $11 \mathrm{~mm} \mathrm{Hg}$. Survival at 1 and 5 years was $99 \%$ and $97 \%$, respectively, and was associated with excellent functional status at last follow-up (98\% with New York Heart Association class I or II limitations). The authors performed an extended septal myectomy through a transaortic approach and placed emphasis on addressing resection of accessory papillary muscle bundles and performed additional techniques to address anomalous findings of the MV leaflets and mitral apparatus. The authors emphasized extending the excision to the apex of the LV and excising aberrant muscle bundles along the root of the papillary muscles and between the apex and LV free wall and between the papillary muscles and free wall.

The series by Wang and colleagues ${ }^{5}$ is important from a number of perspectives. Their experience reinforces that (1) myectomy, performed correctly, is effective in relieving
LVOT obstruction and is associated with very low operative mortality and excellent long-term survival and functional status; (2) the transaortic approach is uniformly successful in addressing obstruction and associated intraventricular anomalies; and (3) intraventricular anomalies are prevalent, and a careful assessment must be performed and anomalies corrected with a number of available surgical techniques. The authors also advocated an extensive resection, including resection of accessory muscle bundles at the apex, which were frequently observed in their series. The authors believed this approach offered possible benefits of enlarging the volume of the middle and apical ventricle while restoring the function of the apical ventricle with increases in cardiac output. These latter claims are not supported by their experience, and further study is required to understand the benefits, if any, of this approach.

Surgical septal myectomy has been performed for more than 50 years and has represented an enduring and effective treatment for obstructive HCM. An improved understanding of the phenotypic patterns of interventricular anomalies has refined the surgical approach and significantly improved the outcomes of this procedure.

\section{References}

1. Gersh BJ, Maron BJ, Bonow RO, Dearani JA, Fifer MA, Link MS, et al. 2011 ACCF/AHA guideline for the diagnosis and treatment of hypertrophic cardiomyopathy: executive summary. J Am Coll Cardiol. 2011;58:2703-38.

2. Maron BJ, Rowin EJ, Casey SA, Maron MS. How hypertrophic cardiomyopathy became a contemporary treatable genetic disease with low mortality shaped by 50 years of clinical research and practice. JAMA Cardiol. March 2, 2016 [Epub ahead of print].

3. Brown ML, Schaff HV. Surgical management of obstructive hypertrophic cardiomyopathy: the gold standard. Expert Rev Cardiovasc Ther. 2008;6:715-22.

4. Said SM, Dearani JA, Ommen SR, Schaff HV. Surgical treatment of hypertrophic cardiomyopathy. Expert Rev Cardiovasc Ther. 2013;11:617-27.

5. Wang S, Cui H, Yu Q, Chen H, Zhu C, Wang J, et al. Excision of anomalous muscle bundles as an important addition to extended septal myectomy for treatment of left ventricular outflow tract obstruction. J Thorac Cardiovasc Surg. 2016;152: 461-8. 